\title{
ПРО ПОБУДОВУ СКІНЧЕННО-ЕЛЕМЕНТНОЇ МОДЕЛІ ВЗАЕМОДІЇ ДВОЗВ'ЯЗНОГО В ПЛАНІ ШТАМПА З ПРУЖНІМ ПІВПРОСТОРОМ
}

У роботі досліджується задача взаємодії двозв'язного в плані штампа у формі трикутного кільця 3 пружнім півпростором. Числові дослідження проведено методом скінченних елементів із застосуванням програмного комплексу ANSYS 2021 R2, y якому створена тривимірна комп'ютерна модель. Досягнуто задовільне узгодження результатів числового моделювання з отриманими раніше аналітичними.

Ключові слова: скінченно-елементна модель, контактна задача, штамп, моделювання, напружено-деформований стан, програмний комплекс ANSYS.

\author{
T.A. Zaytseva, V.V. Zhushman \\ Oles Honchar Dnipro National University
}

\section{THE CONSTRUCTION OF A FINITE-ELEMENT MODEL OF THE INTERACTION OF A DOUBLE-CONNECTED PUNCH WITH AN ELASTIC HALF-SPACE}

The study of contact interaction of bodies is an essential research topic nowadays. The problem of the interaction of a double-connected punch in the form of a triangular ring with an elastic half-space is considered in this work. Due to the fact that solving such problems in an analytical form is a challenging in multiple ways process, the application of numerical methods such as the finite element method and the boundary element method take place.

With the help of the ANSYS software package, a finite-element model of contact interaction of a rigid double-connected punch in the form of a triangular ring with an elastic half-space was created. The numerical simulations using a licensed version of ANSYS 2021 R2 (provided free of charge) were performed. The Static Structural module, ANSYS computer-aided design system, provided access to statics design and finite element analysis. The access to the obtained results and the post-processing took place through the Solutions and Results modules, respectively. Several problems have been solved for punches that have the shape of a triangular ring of different widths. The distribution of pressure under the punch in different sections and the depth of the punch indentation are obtained. The graphs of pressure distribution are constructed. When solving multiple test problems to assess the adequacy of the finite element model, a comparison of numerical results with the results obtained analytically was conducted.

The obtained finite element model can be applied to analyze and predict the load, wear, and destruction of constructions with the contact area in the form of close to a triangular ring. The prospects of the study include solving many problems of analysis of the stressstrain state of the interaction of a punch of complex shape with elastic half-space, as well as groups of punches of complex shape, and analysis of model behavior depending on the

Зайцева Т.А., Жушман В.В., 2021 
rties and the features of an elastic half-space.

Keywords: finite element model, contact problem, punch, stress-strain state, modeling, ANSYS software package.

\author{
Т.А. Зайцева, В.В. Жушман
}

Днипровский национальный университет имени Олеся Гончара

\title{
О ПОСТРОЕНИИ КОНЕЧНО-ЭЛЕМЕНТНОЙ МОДЕЛИ ВЗАИМОДЕЙСТВИЯ ДВУСВЯЗНОГО В ПЛАНЕ ШТАМПА С УПРУГИМ ПОЛУПРОСТРАНСТВОМ
}

В работе исследуется задача взаимодействия двусвязного в плане штампа в форме треугольного кольца с упругим полупространством. Численные исследования проведены методом конечных элементов с применением программного комплекса ANSYS 2021 R2, в котором создана трехмерная компьютерная модель. Достигнуто удовлетворительное согласование результатов численного моделирования с полученными ранее аналитическими.

Ключевые слова: конечно-элементная модель, контактная задача, штамп, напряженно-деформированное состояние, моделирование, программный комплекс ANSYS.

Вступ. Дослідження контактної взаємодії тіл в наш час є актуальною задачею, яка розповсюджується на різні галузі людської життєдіяльності від технологічних процесів до передових наукових досліджень. До них відносяться машинобудування, будівництво, біомеханіка, геологія і багато інших галузей. Вслід за розвитком науки механіки взаємодії, зросла і складність форм тіл, контактування яких досліджується. Розв'язання таких задач в аналітичному вигляді є трудомістким та довгим процесом. Тому для їх вирішення застосовуються числові методи такі як метод скінченних елементів, метод граничних елементів.

Аналіз стану проблеми. Значну роль в розвитку контактних задач відіграють дослідження взаємодії жорстких штампів різної форми 3 пружним півпростором. Так в роботі [1] наведено розв’язок для статичної просторової контактної задачі про вдавлювання близького до плоского штампа з заокругленими краями в пружний шорсткий півпростір. Продовжуються активні дослідження контактних задач з використанням штампів канонічної в плані форми [2]. Залишається вкрай актуальним застосування розроблених аналітичних методів розв'язання контактних задач механіки та пошук нових аналітичних методів [3]. Підходи до розв’язання просторових задач контактної взаємодії довільного у плані штампа 3 пружним півпростором 3 урахуванням тертя i шорсткості наведені у роботі [4]. Також багато уваги приділяється пошуку рішень задач для взаємодії складнопрофільних тіл [5]. Отримано розв'язок просторової контактної задачі для трикутного кільцевого в плані штампа за наявності тертя [6].

Враховуючи розмаїття задач які мають місце в межах механіки взаємодії твердого тіла, не дивним є і розмаїття систем автоматизованого проектування в яких ці задачі розв'язуються. Використання методу скінченних елементів 
надає можливість вирішувати більш складні задачі механіки [7]. Але зазвичай системи автоматизованого проектування накладають певні обмеження на безкоштовні версії, або не в повному обсязі розв'язують поставлену задачу, тому існують і такі системи автоматизованого проектування, які розробляються безпосередньо дослідниками [8].

Постановка задачі. Розглянемо абсолютно жорсткий плоский штамп, що займає в плані область, контур якої обмежений двома рівносторонніми трикутниками. Початок координат розмістимо в точці, що співпадає з центрами описаних кіл навколо зовнішнього і внутрішнього трикутників, що подібні.

Сформулюємо задачу про вдавлення в пружний півпростір циліндричного штампа з плоскою основою під дією вертикальної сили Q, лінія дії якої проходить через початок координат, що співпадає і з центром тяжіння перерізу основи штампа. Поперечний перетин штампа займає двозв'язну область $\Omega$, обмежену двома лініями $\Gamma_{1}, \Gamma_{2}, 3$ рівняннями близькими до рівносторонніх трикутників.

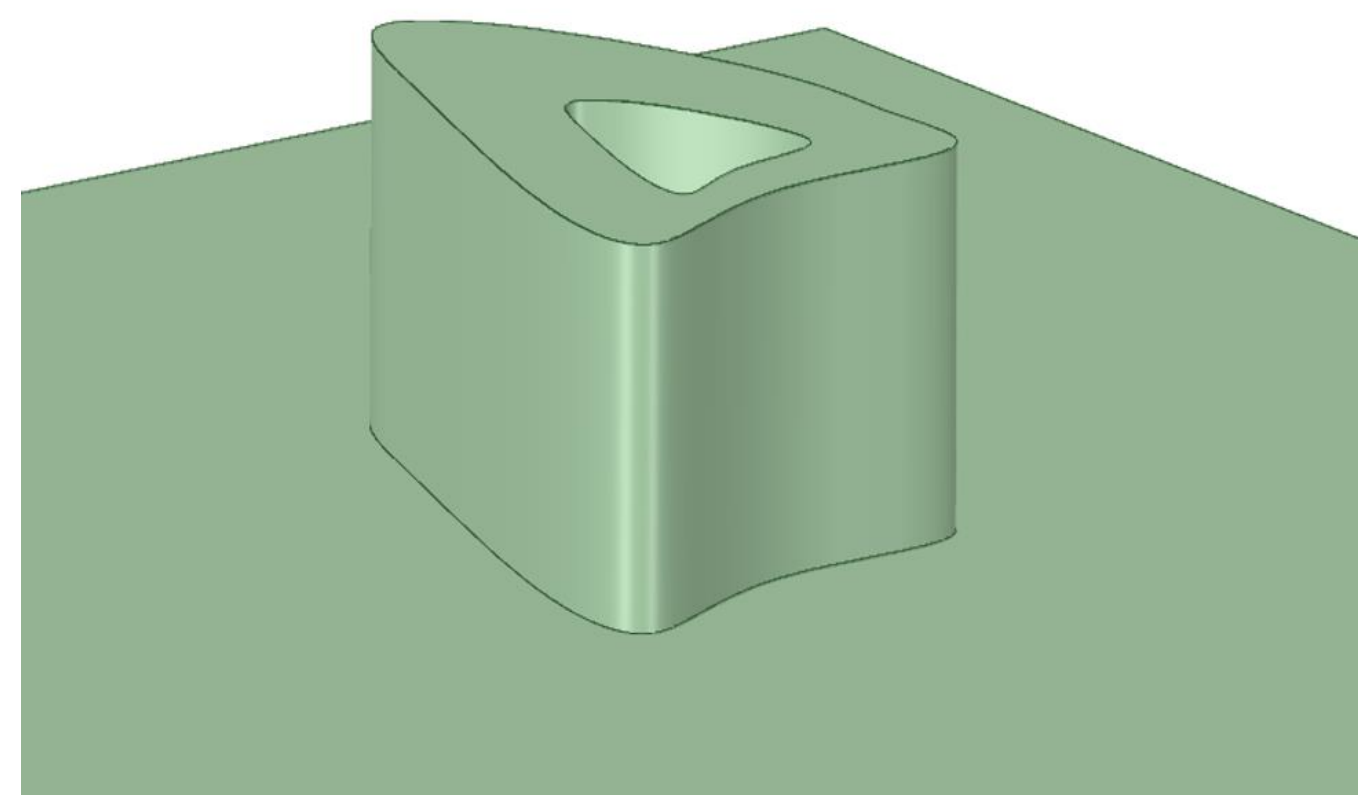

Рис. 1 Система: двозв'язний в плані штамп - пружній півпростір

Позначимо $b$ - радіус кола, описаного навколо зовнішнього трикутника, $a$ - навколо внутрішнього. $a<b$. Рівняння меж $\Gamma_{1}, \Gamma_{2}$ області контакту $\Omega$ в полярній системі координат представимо у наступному вигляді [4]:

$$
\rho_{\Gamma_{1}}=a f(\theta), \quad \rho_{\Gamma_{2}}=b f(\theta),
$$

де $f(\theta)=1+\sum_{i=1}^{\infty} \varepsilon^{i} f_{i}(\theta)$,

Необхідно побудувати скінченно-елементну модель взаємодії пружнього півпростору с жорстким штампом у формі некругового трикутного кільця за допомогою програмного комплексу ANSYS, проаналізувати напружено- 
деформований стан системи та оцінити результати шляхом порівняння 3 отриманими раніш аналітичними [4].

Основний матеріал. Рівновага штампа описується наступними рівняннями:

$$
\begin{gathered}
P=\iint_{\Omega} p(x) \mathrm{d} x, \\
M_{1}=\iint_{\Omega} x_{2} p(x) \mathrm{d} x, \quad M_{2}=-\iint_{\Omega} x_{1} p(x) \mathrm{d} x,
\end{gathered}
$$

де функція $p(x)$ характеризує розподіл тиску під штампом, $P, M_{1}, M_{2}$ - головний вектор і головні моменти прикладених до штампу сил.

Позначимо поступове переміщення, паралельне вертикальній осі $x_{3}$, через $\delta$, а через $\beta_{1}, \beta_{2}$ - проекції вектора малого повороту штампа

$$
x_{3}=0, \quad\left(x_{1}, x_{2}\right) \in \Omega: U_{3}=\delta-\beta_{2} x_{1}+\beta_{1} x_{2} .
$$

Для випадку плоского штампа умова для вертикального переміщення точок області контакту $\Omega$ зводиться до двовимірного інтегрального рівняння першого роду для шуканого розподілу нормального тиску $p(x)$

$$
\delta-\beta_{2} x_{1}+\beta_{1} x_{2}=\frac{1-v}{2 \pi G} \iint_{\Omega} \frac{p\left(x_{1}^{\prime}, x_{2}{ }^{\prime}\right) \mathrm{d} x_{1}{ }^{\prime} \mathrm{d} x_{2}{ }^{\prime}}{\sqrt{\left(x_{1}-x_{1}\right)^{2}+\left(x_{2}-x_{2}\right)^{2}}},
$$

де $v$ - коефіцієнт Пуассона; $\mathrm{G}$ - модуль зсуву.

Шляхом зведення рівнянь задачі для некругового кільця до послідовності систем рівнянь для кругового кільця, у випадку плоского штампа невідомі поступальні переміщення штампа та проекції вектору повороту штампа, було представлено у вигляді рядів за степенями [4]:

$$
\begin{gathered}
\delta=\sum_{i=0}^{\infty} \delta_{i} \varepsilon^{i} ; \\
\beta_{1}=\sum_{i=0}^{\infty} \beta_{1 i} \varepsilon^{i} ; \quad \beta_{2}=\sum_{i=0}^{\infty} \beta_{2 i} \varepsilon^{i} . \\
P(\rho, \theta)=\sum_{k=1}^{\infty} P_{k}(\rho, \theta) \varepsilon^{k}
\end{gathered}
$$

Було отримано [4] контактний тиск, обмежуючись в розвиненні (8) другою степеню $\varepsilon$, тобто першими трьома наближеннями. Наприклад, тиск під трикутним кільцевим штампом, коли $b=2 a$, в точках $\left(\rho, \theta_{*}\right)$ променя, який ви- 
ходить 3 початку координат та перетинає зовнішній і внутрішній контури області контакту в точках $\left(\rho_{\Gamma 1}, \theta_{*}\right)$ і $\left(\rho_{\Gamma 2}, \theta_{*}\right)$, відповідно, визначено залежністю:

$$
p(\rho, \theta)=P_{0}+\varepsilon P_{1}+\varepsilon^{2} P_{2},
$$

де $\varepsilon=0,3697, \varepsilon^{2}=0,1367, P_{0}=Q \sigma_{0}$,

$$
\begin{gathered}
P_{1}=Q\left[2 \sigma_{0}+\left(0,0006776 \sigma_{0}-0,02418 \sigma_{1}\right) \cos 2 \theta_{*}\right], \\
P_{2}=Q\left[2,9821 \sigma_{0}+0,000864 \sigma_{1}+\left(0,0002033 \sigma_{0}-\right.\right. \\
\left.-0,07254 \sigma_{1}\right) \cos 2 \theta_{*}+\left(0,034750 \sigma_{0}+0,2347 \sigma_{1}+0,01231 \sigma_{2}-0,4585 \sigma_{3}\right) \cdot \\
\cdot \cos 4 \theta_{*}+\left(02357 \sigma_{0}+0,06788 \sigma_{1}\right) \rho_{\Gamma_{1}} / \rho \cos \theta_{*}+\left(0,7458 \sigma_{0}-\right. \\
\left.-0,7204 \sigma_{1}+0,3340 \sigma_{2}\right) \rho_{\Gamma_{1}} / \rho \cos 3 \theta_{*}+0,08077 \mid \sigma_{0}^{\prime}\left(\rho / \rho_{\Gamma_{2}}-\right. \\
\left.\left.-\frac{\rho^{2}}{\rho^{2} \Gamma_{2}} \frac{b}{a+b}-\frac{a}{a+b}\right)-3 \frac{\rho}{\rho_{\Gamma_{2}}} \frac{b}{a+b} \sigma_{0}\right] \cdot \cos \theta_{*}+ \\
\left.+1,2880 \sigma_{0}^{\prime}\left(\frac{\rho}{\rho_{\Gamma_{2}}}-\frac{\rho^{2}}{\rho^{2} \Gamma_{2}} \frac{b}{a+b}-\frac{a}{a+b}\right) \cdot \cos 3 \theta_{*}\right] . \\
\sigma_{i}=\pi \gamma / 2 \sum_{k, p=0}^{\infty}\left[\left(\rho / \rho_{\Gamma_{2}}\right)^{2 k} \alpha_{p k}^{(i)}+\left(\rho_{\Gamma_{1}} / \rho\right)^{2 k+3} \beta_{p k}^{(i)}\right](a / b)^{p} .
\end{gathered}
$$

Вираз для вертикального переміщення штампа приймає вигляд:

$$
\delta=\frac{1-v}{G} \frac{Q}{4 b \gamma^{-1}}\left(1+\varepsilon+0,9818 \varepsilon^{2}\right) .
$$

Програмне середовище моделювання. Для моделювання процесу вдавлення плоского штампа у формі трикутного кільця в плані в пружний півпростір було використано програмний комплекс ANSYS. Використовувалась студентська версія ANSYS STUDENT 2021 R2 [7], яка надає безкоштовний доступ до набору ANSYS Workbench в рамках наукових досліджень. Цей комплект включає ANSYS Mechanical, ANSYS CFD, ANSYS Autodyn, ANSYS SpaceClaim та ANSYS DesignXplorer. Конфігурація робочої станції на якій відбувався процес моделювання Windows 10 Home (64-bit, Version 21H1, OS build 19043.1237), процесор AMD Ryzen 5 4500U with Radeon Graphics $2.38 \mathrm{GHz}$, та 16.0 GB оперативної пам'яті.

Модуль Static Structural, системи автоматизованого проектування ANSYS, надав доступ до проектування в рамках статики та проведення скінченно- 
елементного аналізу. Підмодуль Engeneering Data, надав можливість керувати фізичними та механічними властивостями матеріалів. Design Modeler (пункт Geometry в вкладці Component Systems) надав можливість зпроектувати та згенерувати вихідну геометрію з якою проводилась подальша робота. Генерація скінченно-елементної сітки та іï додаткові налаштування відбувались в модулі Meshing. Доступ до отриманих результатів та постпроцесінгу проходив через модулі Solutions та Results відповідно.

Результати моделювання в ANSYS. Була створена геометрія тіла штампа та пружного півпростору. Для даної геометрії була побудована скінченноелементна сітка. Для підтримання призм різного виду було використано метод Multi Zone. Для отримання більш детальної сітки в області зони контакту у формі трикутного кільця була використана функція Sizing, яка надає можливість корегувати розмір сітки локально в рамках вказаної геометрії. Регулярність сітки для заданої геометрії була досягнута за допомогою інструментy Face Meshing. Чисельні експерименти по вибору сітки надали змогу отримати найбільш вдале розбиття поверхні контакту. До згенерованої сітки були добавлені призматичні шари, які дозволяють більш чітко досліджувати зону прикладення сил через контактну взаємодію штампа 3 пружним півпростором. На рис. 2, 3 наведено приклад скінченно-елементної сітки на поверхні деформованого півпростіру під дією трикутного кільцевого в плані штампа.

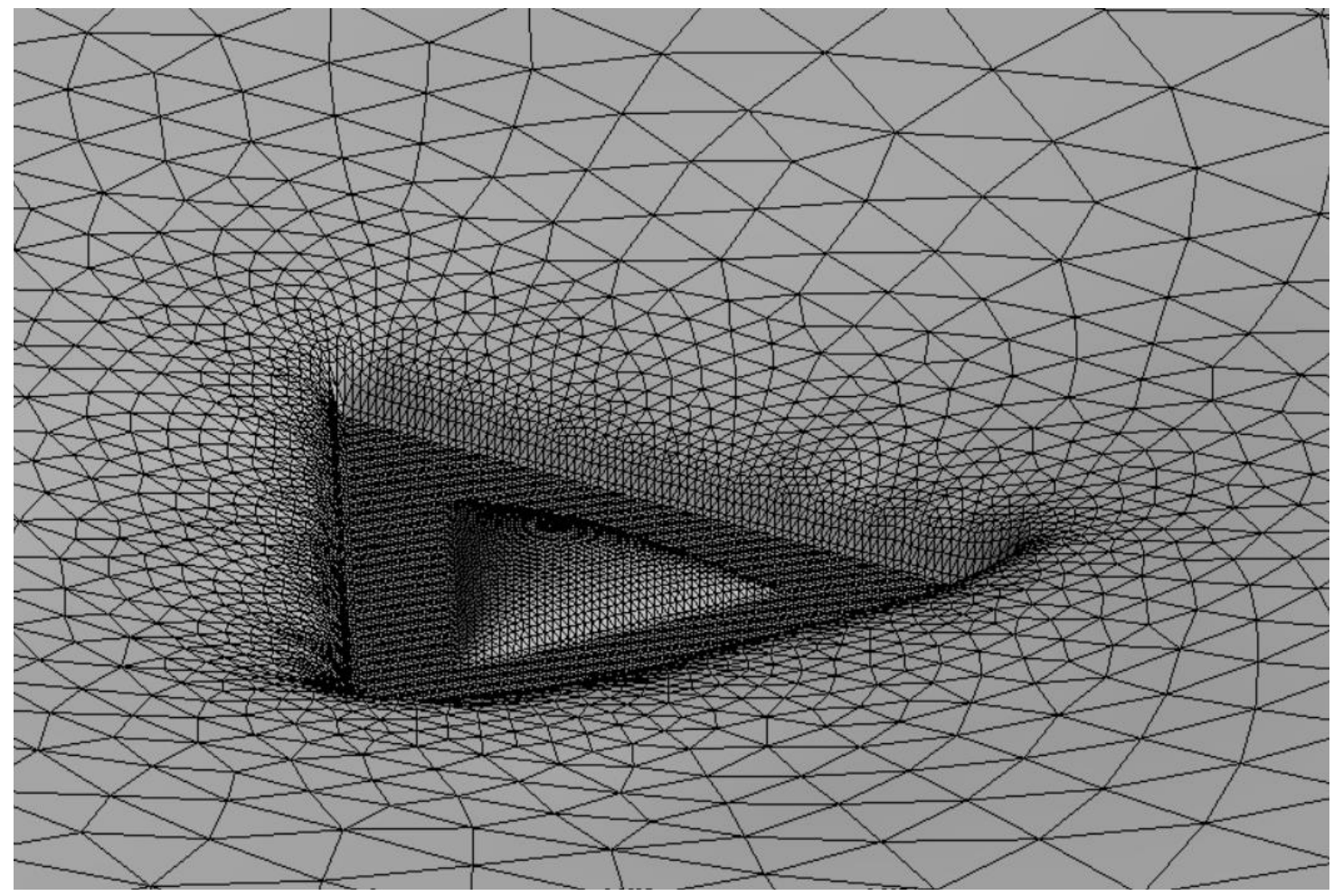

Рис. 2 Скінченно-елементна сітка на поверхні деформованого півпростору. 


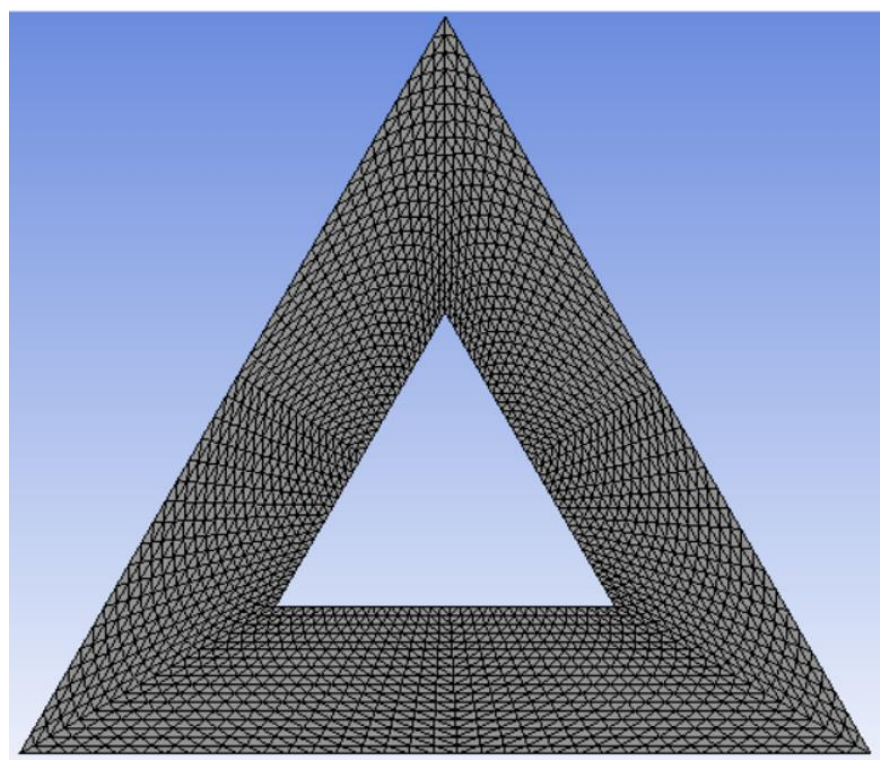

Рис. 3 Область контакту

Після задання всіх необхідних параметрів, граничних умов та вирішення відповідної математичної моделі було проведено аналіз, використовуючи post processing отриманих результатів. Було досліджено нормальне напруження, що виникає в процесі пружної деформації півпростору під дією штампа. Для отримання таких результатів в ANSYS було використано спеціальний модуль Linearized Stress.

На рис. 4 представлено графіки результатів розподілу нормального тиску під кільцевим трикутним штампом для даних отриманих аналітичним шляхом ( 1 - суцільна крива) для випадка, коли $a=0,6 b$ в точках $\left(\rho, \theta_{*}\right)$ променя, який виходить 3 початку координат та перетинає зовнішній і внутрішній контури області контакту в точках $\left(\rho_{\Gamma 1}, \theta_{*}\right)$ i $\left(\rho_{\Gamma 2}, \theta_{*}\right)$ та чисельним шляхом ( 2 - пунктирна крива).

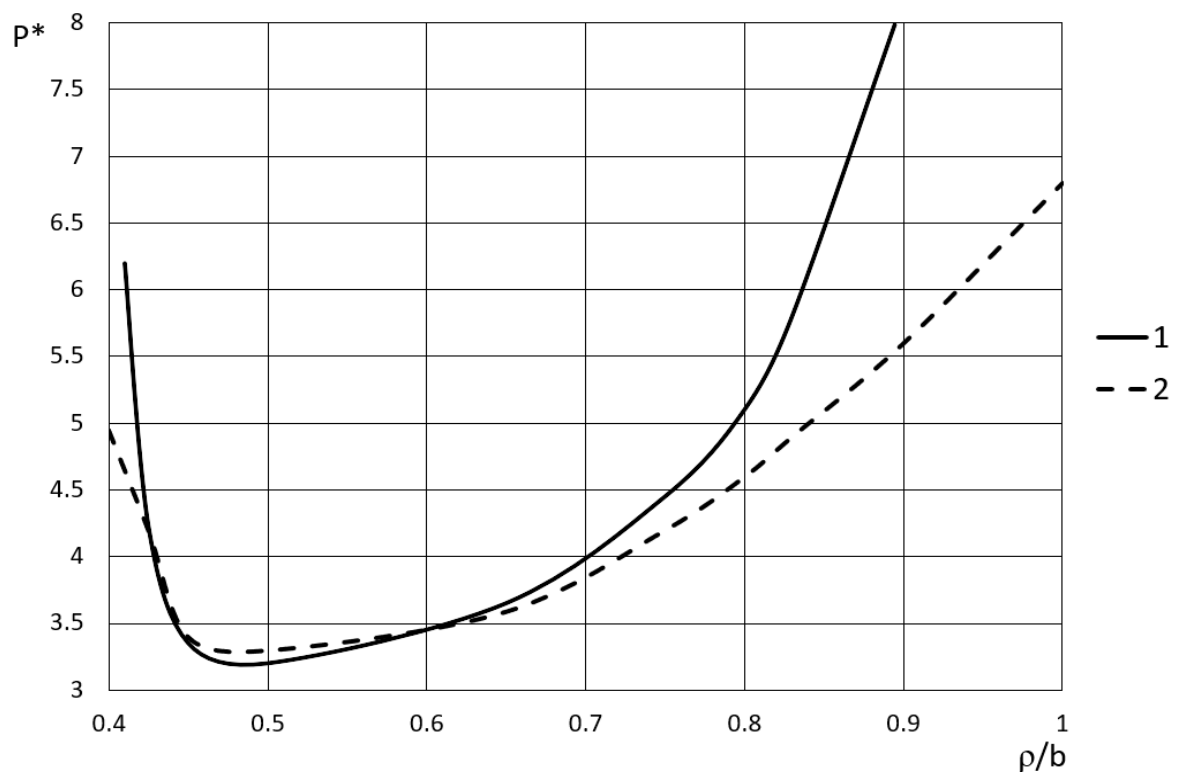

Рис. 4 Розподіл нормального тиску в перерізі $\theta=0$ 
Результати дослідження показали що нормальні напруження, отримані аналітичним шляхом на краях зони контакту значно вищі за чисельні та прямують до нескінченності. Треба відзначити, що напруги ростуть швидше iз зовнішньої сторони кільця. Результати, що отримані за чисельними розрахунками досягають своїх максимальних значень на границях контакту. Значний розбіг в отриманих результатах на границях контакту, обумовлено різницею у підходах між аналітичним і чисельним розв'язанням такого класу задач. Також треба мати на увазі особливості, що мають місце при розрахунку напруг у кутових зонах контактуючих тіл. В зоні контакту в межах середньої третини кільця, але трохи ближче до внутрішнього контуру, значення нормальних напружень майже близькі. Відносна різниця у розрахунках нормального тиску у зоні середньої третини кільця не перевищую 8\%. Також існують області де присутні майже повне співпадіння результатів. Зі зменшенням ширини кільця напруги значно зростають. Результати чисельного розв'язку знаходяться в рамках допустимих відхилень.

Висновки та перспективи досліджень. Використовуючи систему автоматизованого проектування ANSYS була створена модель контактної взаємодії плоского двозв'язного в плані штампа у формі трикутного кільця з пружнім півпростором. Побудовані графіки розподілу напружень. Виконано порівняння отриманих результатів в середині зони контакту з результатами аналітичного розв'язку, яке продемонструвало, задовільне узгодження, що свідчить про адекватність запропонованої моделі. На основі отриманих результатів планується майбутня робота над контактною взаємодією двох складнопрофільних тіл, більш детальний аналіз особливих зон взаємодії тіл, наприклад, на краях зон контакту, у кутах трикутних областей та ін.

\section{Бібліографічні посилання}

1. Мартиняк Р. М., Приходько О.В Задача про вдавлювання близького до плоского штампу в пружний шорсткий півпростір. Проблеми обчислювальної механіки і мічності конструкиій. 2020. (31). С. 66-77.

2. Максимук О.В., Сачук Ю.В. Особливості контактної взаємодії штампів канонічної форми із пружним півпростором. Сучасні проблеми механіки і математики. У 3-х т. Під. заг. ред. Р.М. Кушніра, Б.Й. Пташника. Львів: Ін-т прикл. Проблем механіки і математики ім. Я.С. Підстригача НАН України, 2013. Т. 1. С. 72-73.

3. Roitman A.B., Shishkanova, S.F. The solution of the annular punch problem with the aid of recursion relations. Soviet Applied Mechanics. 1973. №9 (7). pp. 725-729.

4. Зайцева Т.А., Шишканова Г.А. Розв'язання просторових контактних задач для некласичних багатозв’язних областей. Дніпро: Вид-во ДНУ, 2011. 192 с.

5. Ткачук Н.Н., Ткачук Н.А. Контакт сложнопрофильных тел: связанная задача анализа напряженно-деформированного состояния и геометрического синтеза. Механіка та машинобудування. 2011. № 2. С. 75-86.

6. Шишканова А.А., Зайцева Т.А. Решение пространственной контактной задачи о штампе с двусвязным основанием, ограниченным треугольниками, при наличии трения. 
ISSN 2074-5893 Питання прикладної математики і математичного моделювання. Випуск 21

Актуальні проблеми механіки суцільного середовища $і$ міџңності конструкцій: зб. матер. міжнародної конф. Дніпропетровськ. 2007. С. 91-93.

7. Ansys Free Student Software Downloads. URL: https://www.ansys.com/academic/freestudent-products (дата звернення: 18.09.2021).

8. Zhushman V., Zaytseva T., Hurko O. The latest information technologies for modeling problems of mechanics of deformed solid. Modern scientific and technical research in the context of language space (in English): materials X Region. scientific-practical conf. young scientists and students, May 13, 2021. Dnipro: Gerda, 2021. 204 p. pp. 171-173.

Надійшла до редколегії 18.06. 2021. 